Int. J. Mol. Sci. 2003, 4, 503-511

International Journal of

Molecular Sciences

ISSN 1422-0067

(C) 2003 by MDPI

www.mdpi.org/ijms/

\title{
Modelling of Octahedral Manganese II Complexes with Inorganic Ligands: A Problem with Spin-States
}

\author{
Bartosz Trzaskowski $^{1}{ }^{*}$, Andrzej Les ${ }^{1}$ and Ludwik Adamowicz ${ }^{2}$ \\ ${ }^{1}$ Department of Chemistry, Warsaw University, Pasteur 1 Street, 02-083 Warsaw, Poland \\ ${ }^{2}$ Department of Chemistry, University of Arizona, Tucson, Arizona 85721, U.S.A. \\ Tel.: +48 (22) 8220211 ext.282, Fax: +48 (22) 82223 09, E-mail: trzask@tiger.chem.uw.edu.pl \\ URL: http:// tiger.chem.uw.edu.pl/staff/trzask/trzask_en.html \\ * Author to whom correspondence should be addressed.
}

Received: 10 April 2003 / Accepted: 18 June 2003 / Published: 30 August 2003

\begin{abstract}
Quantum mechanical ab initio UHF, MP2, MC-SCF and DFT calculations with moderate Gaussian basis sets were performed for $\mathrm{MnX}_{6}, \mathrm{X}=\mathrm{H}_{2} \mathrm{O}, \mathrm{F}^{-}, \mathrm{CN}^{-}$, manganese octahedral complexes. The correct spin-state of the complexes was obtained only when the counter ions neutralizing the entire complexes were used in the modelling at the B3LYP level of theory.
\end{abstract}

Keywords: Ab Initio, density functional theory, spin-state, manganese.

\section{Introduction}

It is usual to assume that octahedral manganese II complexes are high-spin molecules and such an assumption has been widely used in almost every work concerning this type of complexes [1-2]. There are many arguments, both experimental and theoretical, which support this assumption, but some of them can be questioned. Since Mn II complexes are often present in active centers of enzymes, e.g., superoxide dismutaze [3], peroxidaze [4], aminopeptidase [5], sialyl and fucosyl transferase [6-8] or various integrins [9-10], it is important to improve our understanding of their structures and properties, and to explain the discrepancies between the theory and experimental data occurring. In this work some basic concepts concerning the octahedral Mn II complexes are discussed in view of the results of the comparative calculations performed. 
According to the simple theory of transition metal complexes - the crystal field theory (CFT) [1113] - the metal cation is affected by the purely electrostatic field created by the nearest neighbour ligands represented by point charges or point dipoles. Despite its simplicity the CFT method leads to very useful results that in most cases are qualitatively in agreement with the experimental data.

The CFT assumes that the 5-fold degeneracy of the cation d-orbitals is removed when the central ion is surrounded by a set of negative charges or negative ends of dipoles representing the ligands. Surrounding the cation by six ligands splits the orbitals into two sets with different energies - the triply degenerated $t_{2 g}$ level and the doubly degenerated $e_{g}$ level. The occupation of the $t_{2 g}$ and $e_{g}$ orbitals is dependent on the difference between the splitting energy (energy difference between the $t_{2 g}$ and $e_{g}$ levels) and the pairing energy (energy of placing two electrons with different spins in the same orbital). If the pairing energy is greater than the splitting energy we get a high-spin state; in other cases the complex is in a low-spin state [11-15]. Mean pairing energies for most ions and splitting energies for many ligands can be estimated based on the spectroscopic data. Using these data it is possible to determine the spin of most complexes.

The Molecular Orbital Theory, which uses group theory and quantum mechanics, can be an alternative tool for predicting the spin-state of the transition metal complexes. Its advantage is to give not only qualitative, like CFT, but also quantitative results, concerning the spin-state and the structure of the complex.

There has been extensive research on manganese (II) complexes with water ligands, both experimental, including X-ray and EXAFS [16-20], and theoretical using the ab-initio SCF method [21], the molecular dynamics simulation [22-23] and very recently also combined quantum mechanical/molecular mechanical and Monte Carlo simulations [24-26]. The $\mathrm{Mn}-\mathrm{H}_{2} \mathrm{O}$ complex can be a model species for all high-spin manganese complexes, which include the majority of all Mn II complexes. This is because for Mn II the pairing energy is very high and there are only few known structures with ligands creating a sufficiently strong field to force the complex into the low-spin state. The low-spin complexes, e.g. $\left[\mathrm{Mn}(\mathrm{CN})_{6}\right]^{4-}$ and $\left[\mathrm{Mn}(\mathrm{CNR})_{6}\right]^{4-}\left(\mathrm{R}=\mathrm{CH}_{3}, \mathrm{C}_{2} \mathrm{H}_{5}\right)$, have been studied much less frequently than the high-spin complexes because their occurrence in biological and other systems is very rare.

In the present work we intended to determine the spin-states of several manganese complexes shown on figure 1, including low-spin $\mathrm{Mn}(\mathrm{CN})_{6}{ }^{4-}$ complex, but we encountered difficulties when using models reduced to the first coordination shell. An improved model, where the counter ions are added, were subsequently used and the results obtained for this improved model are discussed in this work. The calculations proposed in this paper concentrate on DFT methods since density functional theory became a standard tool for theoretical modelling of biological systems. For comparison, the ab initio calculations (UHF, MP2, MC-SCF, medium-size basis sets) were also performed.

According to the CFT theory the two ligands, $\mathrm{H}_{2} \mathrm{O}$ and $\mathrm{F}^{-}$, considered in this study should form high-spin-state complexes with the manganese cation. The third complex, $\left[\mathrm{Mn}(\mathrm{CN})_{6}\right]^{4-}$, should appear in the low-spin state due to the strong electrostatic perturbation created by the ligands [14-15, 27-28]. 


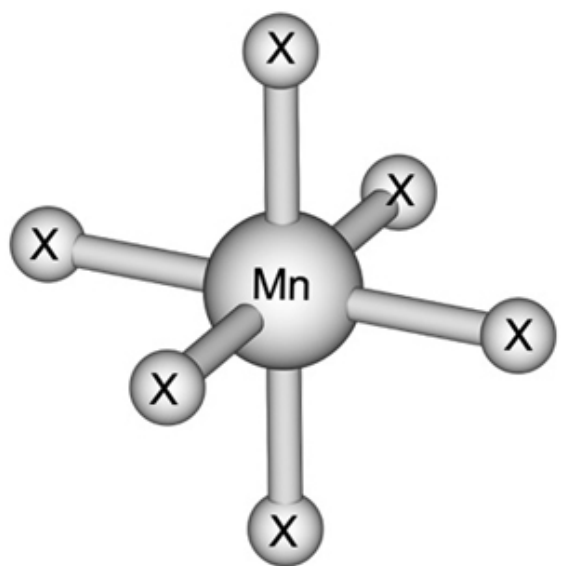

Figure 1. $\mathrm{MnX}_{6}$ model, $\mathrm{X}=\mathrm{H}_{2} \mathrm{O}, \mathrm{F}^{-}, \mathrm{CN}^{-}$.

\section{Computational Details}

The geometries of the metal complexes were fully optimized assuming several possible multiplicities (2, 4 or 6). The ab initio UHF [29-31], MP2 [32], and MC-SCF [33-34], as well as the density functional BLYP [35-36], SVWN [37-38], B3PW91 [39-40] and B3LYP [39,36] methods were used with the standard 3-21G*, 6-31G*, 6-31G** and AhlrichsVDZ basis sets. The starting geometry in each calculation was the regular octahedral structure with the Mn-ligand distance set to 2.2 Angstroms (the mean ionic radius of manganese complexes [41-42]).

Also, a set of calculations using different Mn-ligand distances as the starting points for the geometry optimization was performed. In these calculations the Mn-ligand distance was set to 2.0, 2.1, 2.3, 2.4 and 2.5 Angstroms, respectively, in order to check the influence of the choice of the starting point on the final geometry and on the spin-state of the lowest energy structure.

Complexes with other central ions were also examined for comparison using the UHF and B3LYP methods and the 6-31G* basis set. Two transition metal cations, Fe II and Fe III, and their complexes with $\mathrm{H}_{2} \mathrm{O}$ and $\mathrm{CN}^{-}$ligands were considered in the calculations. As in the manganese II case, both Fe II and Fe III form high-spin complexes with water ligands and low-spin complexes with the $\mathrm{CN}^{-}$ions [27-28]. The initial geometry in these calculations was also chosen to be the regular octahedral structure with the Fe-ligand distances set to 2.55 Angstroms.

To estimate the role of the counter-ions, usually omitted in simplified modeling of the transition metal complexes, $\mathrm{Na}^{+}$cations were added to the model. Two model systems with four $\mathrm{Na}^{+}$ions neutralizing the $\mathrm{MnX}_{4}^{4-}, \mathrm{X}=\mathrm{F}^{-}, \mathrm{CN}^{-}$, complexes were built. Again the starting point for the B3LYP and MC-SCF structure calculations with the $3-21 \mathrm{G}^{*}$ and $6-31 \mathrm{G}^{*}$ basis sets was chosen to be the regular octahedral complex, in which the Mn-ligand distance was set to 2.2 Angstroms. $\mathrm{Na}^{+}$ions were placed at the distance consistent with the radius of the second hydration shell of the manganese II complexes taken form experimental data available [43-47]. The energy differences between the high-spin and low-spin states of the uncharged complexes were compared to the energies obtained for the negatively charged ones. 
The calculations were performed on the single-processor NEC SX-4B/2A and four-processor Cray SV1 supercomputers using Gaussian 98 [48], and on Intel Pentium III using the Jaguar 4.0 [49] and Dalton 1.2 [50] software.

\section{Results and Discussion}

The simulations carried out using the DFT methods revealed a very poor convergence of the iterative procedure for finding the solution of the Kohn-Sham equations. In many cases the geometry optimization of the Mn complexes using DFT methods diverged, which in turn made it impossible to determine the total energy of the complexes. On the other hand UHF converged in all cases, but it frequently gave completely unrealistic and wrong geometries, what is a known problem within the Hartree-Fock theory.

For the cases where satisfactory convergence was obtained the geometries of the complexes remained almost perfectly octahedral, in agreement with the experimental data. The distances between the central cation and the nearest-neighboring atoms of the ligands were also in good agreement with both the experimental data $[29,16-20]$ and with the previous theoretical calculations [30,21-26,2].

The complexes with the lowest total molecular energies corresponded to the high-spin complexes in all of the above mentioned calculations. According to the CFT theory and in agreement with the experimental data, the octahedral complexes of $\mathrm{Mn}(\mathrm{II})$ with six $\mathrm{H}_{2} \mathrm{O}$ ligands or six $\mathrm{F}^{-}$ions should appear in the high-spin state, whereas the cyanide complex should be in the low-spin state. The highspin state of $\mathrm{Mn}\left(\mathrm{H}_{2} \mathrm{O}\right)_{6}{ }^{2+}$ complex was confirmed by the calculations, but, according to the calculations the $\left[\mathrm{Mn}(\mathrm{CN})_{6}\right]^{4-}$ complex should also exist in the high-spin state and the calculations failed to reproduce this feature. Such a situation was observed independently on the method (UHF, MP2, BLYP, SVWN, B3PW91, B3LYP, MC-SCF) and on the basis set $\left(3-21 \mathrm{G}^{*}, 6-31 \mathrm{G}^{*}, 6-31 \mathrm{G}^{* *}\right)$ used. The energy difference between the high and the low-spin state was in all cases high enough to favor the high-spin state.

Table 1. Energy difference between high-spin and low-spin states of $\mathrm{MnX}_{6}$ complexes using different calculation methods; $\Delta \mathrm{E}=\mathrm{E}$ (high-spin) $-\mathrm{E}$ (low-spin)

\begin{tabular}{ccccc}
\hline complex & $\begin{array}{c}\mathrm{UHF}^{\mathrm{a}} \\
(\mathrm{kcal} / \mathrm{mol})\end{array}$ & $\begin{array}{c}\mathrm{B} 3 \mathrm{LYP}{ }^{\mathrm{a}} \\
(\mathrm{kcal} / \mathrm{mol})\end{array}$ & $\begin{array}{c}\mathrm{MP}^{\mathrm{a}} \\
(\mathrm{kcal} / \mathrm{mol})\end{array}$ & $\begin{array}{c}\mathrm{MC}-S C F^{\mathrm{b}} \\
(\mathrm{kcal} / \mathrm{mol})\end{array}$ \\
\hline$\left[\mathrm{Mn}\left(\mathrm{H}_{2} \mathrm{O}\right)_{6}\right]^{2+}$ & -149 & -102 & -157 & -105 \\
{$\left[\mathrm{MnF}_{6}\right]^{--}$} & +57 & +56 & -118 & -132 \\
{$\left[\mathrm{Mn}(\mathrm{CN})_{6}\right]^{4-}$} & -92 & -176 & -352 & -102 \\
\hline
\end{tabular}

\footnotetext{
${ }^{\mathrm{a}}$ in $6-31 \mathrm{G}^{*}$ basis set.
}

${ }^{\mathrm{b}}$ in AhlrichsVDZ basis set: F-(7s4p|3s2p); Na-(10s5p|4s1p); Mn-(14s8p5d|5s2p2d); the MCSCF wavefunction for the lowspin state $(S=2)$ was composed of 75 configurations ( 5 electrons on 5 active orbitals, remaining doubly occupied orbitals assumed inactive); for the high-spin state $(S=6)$ the wave function corresponded to a single configuration (5 electrons on 5 active orbitals) 
Interestingly, the predicted spin-state of the $\left[\mathrm{MnF}_{6}\right]^{4-}$ complex varied depending on the calculation method and basis set used. The UHF method predicted the preference of the high-spin state within the $3-21 G^{*}$ basis set what is in agreement with the experimental data but failed in the calculations using larger basis set. When the B3LYP functional within the DFT theory was used, the pairing of the electrons forced the system to convert into the low-spin state, but on MP2 or MC-SCF levels of theory the results were again correct.

Another interesting observation is the fact that the distances between the central ion and the ligands are much shorter for the low-spin complexes than for the high-spin complexes. The Mn-X bond shortening ranges from 0.04 to 0.4 Angstroms. Thus it is clear that the spin-state of the complex has a non negligible effect not only on its electronic structure but also on the geometry of the complex. On the other hand the electrostatic perturbation produced by $\mathrm{CN}^{-}$anions or any other ligand directly depends on the distance between the central ion and the ligands. Ligands laying closer to the manganese cation can produce a stronger electric field, which in turn can affect the spin-state of the complex. To investigate this effect a set of calculations, in which the $\mathrm{Mn}-\mathrm{X}$ distance in the starting point of the geometry optimization was set to 2.0, 2.1. 2.3, 2.4 and 2.5 Angstroms, respectively, was performed. The results were compared to the previous calculations where the starting distance was set to 2.2 Angstroms. After the optimizations were completed there was no significant change of the geometry of the complex, and $\left[\mathrm{Mn}(\mathrm{CN})_{6}\right]^{4-}$ remained in the high-spin state.

A similar situation was observed in the case of the Fe II and Fe III complexes. Non-correlated calculations (UHF) again did not correctly predict the spin-state of the Fe charged complexes. Moreover the methods with the electron correlation included (DFT/B3LYP) also failed to predict the spin-state of the iron complexes. Interestingly, for the Fe complexes almost no convergence problems appeared in the calculations.

The next step in the calculations was to estimate the role of the counter-ions usually omitted in simplified modeling of the transition metal complexes, although they can noticeably alter the strength of the ligand field. In those calculations we used four $\mathrm{Na}^{+}$ions to neutralize the manganese $\mathrm{MnX}_{4}{ }^{4-}$, $\mathrm{X}=\mathrm{F}^{-}, \mathrm{CN}^{-}$, complexes. Such a representation with the entire complex being uncharged seems to be closer to the situation found in the real systems. Four different complexes were studied using the B3LYP fuctional and the two different basis sets used in the calculations of the charged complexes. We also used the MC-SCF method in the calculations. As before the starting point in the geometry optimizations was chosen to be the regular octahedral complex in which the Mn-ligand distance was set to 2.2 Angstroms. In Table 2 the energy differences between the high-spin and low-spin states of the uncharged complexes are compared to the corresponding negatively charged states.

The results from Table 2 show that adding counter-ions to the manganese complexes is crucial in obtaining the correct spin-state at the B3LYP level of theory. In the case of $\mathrm{Na}_{4}\left[\mathrm{Mn}(\mathrm{CN})_{6}\right]$ complex the low-spin state was obtained using a small basis set, such as $3-21 \mathrm{G}^{*}$. Unfortunately the calculation with a larger basis set $\left(6-31 \mathrm{G}^{*}\right)$ did not confirm this result - in fact it showed again that the high-spin 
Table 2. Energy difference between high-spin and low-spin states of $\left[\mathrm{MnX}_{6}\right]^{4-}$ and $\mathrm{Na}_{4}\left[\mathrm{MnX}_{6}\right]$ complexes using different calculation methods; $\Delta \mathrm{E}=\mathrm{E}$ (high-spin) $-\mathrm{E}$ (low-spin)

\begin{tabular}{ccccc}
\hline complex & $\begin{array}{c}\text { B3LYP/3-21G* } \\
(\mathrm{kcal} / \mathrm{mol})\end{array}$ & $\begin{array}{c}\mathrm{B} 3 \mathrm{LYP} / 6-31 \mathrm{G}^{*} \\
(\mathrm{kcal} / \mathrm{mol})\end{array}$ & $\begin{array}{c}\mathrm{MP} 2 / 6-31 \mathrm{G}^{*} \\
(\mathrm{kcal} / \mathrm{mol})\end{array}$ & $\begin{array}{c}\text { MC-SCF/ } \\
\text { AhlrichsVDZ } \\
(\mathrm{kcal} / \mathrm{mol})\end{array}$ \\
\hline$\left[\mathrm{Mn}(\mathrm{CN})_{6}\right]^{4-}$ & -188 & -176 & -352 & -102 \\
$\mathrm{Na}_{4}\left[\mathrm{Mn}(\mathrm{CN})_{6}\right]$ & +119 & -16 & -44 & -53 \\
{$\left[\mathrm{MnF}_{6}\right]^{4-}$} & +126 & +56 & -118 & -171 \\
$\mathrm{Na}_{4}\left[\mathrm{MnF}_{6}\right]$ & +207 & -25 & -131 & -129 \\
\hline
\end{tabular}

${ }^{a}$ see footnote to Table 1 .

state was preferred. However the difference between the preferred high-spin state and the low-spin state was much smaller than in the case of $\mathrm{Mn}(\mathrm{CN})_{6}{ }^{4-}$ complex. The same situation can be observed using the MP2 and MC-SCF calculations. In the case of the second complex, $\mathrm{Na}_{4}\left[\mathrm{MnF}_{6}\right]$, the small basis set did not produce correct results, but with the larger $6-31 \mathrm{G}^{*}$ basis set the complex reached the correct high-spin state.

The influence of the counter-ions on the electronic structure of manganese complexes at the B3LYP/3-21G* level was observed by considering the gap between the highest occupied (HOMO) and lowest unoccupied (LUMO) molecular orbitals in these systems (fig. 2). In the case of the negatively charged $\mathrm{Mn}(\mathrm{CN})_{6}{ }^{4-}$ complex, the gap between HOMO an LUMO was quite large while in the neutral complexes the gap was considerably smaller. It seems that a small gap between HOMO and LUMO in

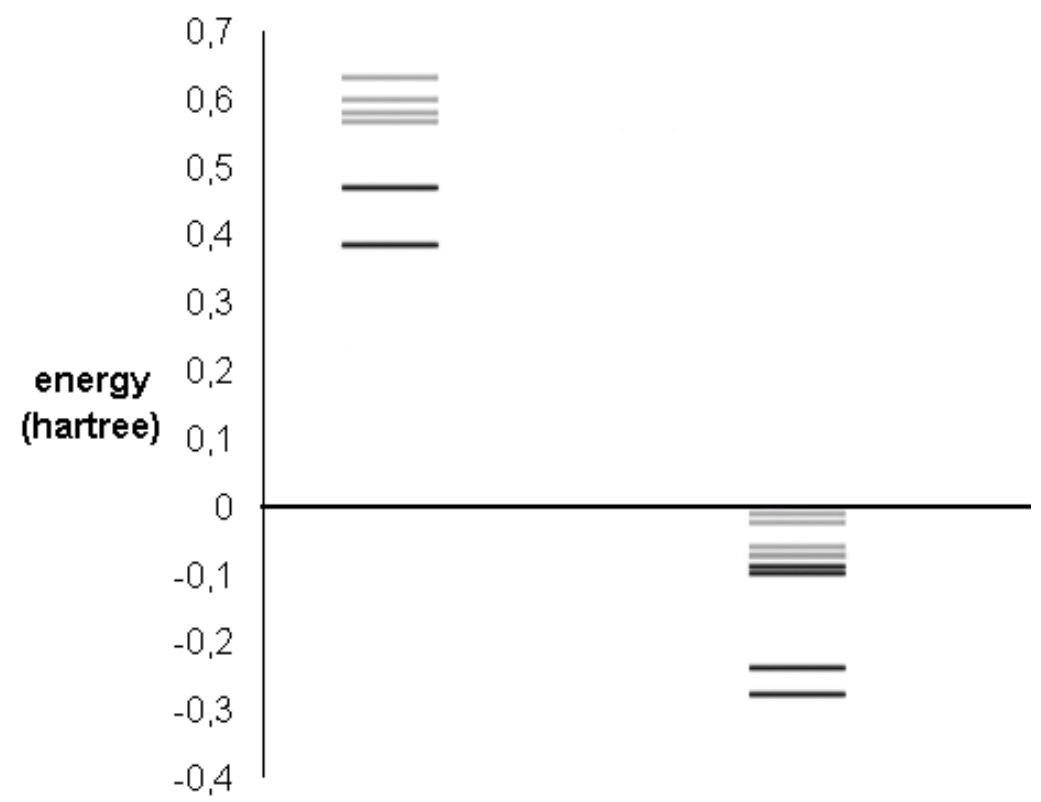

Figure 2. $\left[\mathrm{MnCN}_{6}\right]^{4-}$ (on the left) and $\mathrm{Na}_{4}\left[\mathrm{MnCN}_{6}\right]$ (on the right) orbitals calculated at B3LYP/3-21G* level. Black color denotes occupied, and gray color denotes unoccupied orbitals. The gap between between HOMO and LUMO for the $\mathrm{Na}_{4}\left[\mathrm{MnCN}_{6}\right]$ complex is much smaller than that for the $\left[\mathrm{MnCN}_{6}\right]^{4-}$. 
the neutral complex facilitates to accommodate the correct spin-state easier than in the negatively charged complexes. However, adding counter-ions is not a remedy to alleviate the problems with theoretical prediction of correct spin state. In the case of the ions creating a weak ligand field, the calculations with the $\mathrm{Na}^{+}$cations reproduced well the desired high-spin state, but in the case of the $\mathrm{CN}^{-}$ ligands UHF, MC-SCF and MP2 methods failed to predict the correct, low-spin state.

\section{Summary and Conclusions}

Theoretical studies of manganese octahedral complexes with the central ion surrounded by six small ligands showed that reproducing the correct spin-state of such complexes in the calculations can be a difficult problem. This problem occurred at different levels of theory and did not go away despite changing the basis set. In addition, changing the initial geometry in the calculation of the optimal structure did not lead to the correct results.

Adding counter-ions to the model in order to correct the problem with the wrong spin state worked at the DFT level of theory when some basis sets were used, but did not work for other basis sets. The counter-ions interacting with the ligands caused reduction of the orbital energy gaps between the various spin-states of the Mn complexes. This in turn led to significant alteration of the molecular and electronic structure of the complexes.

Including counter-ions in the calculations failed to predict the low-spin states for the low-spin complexes at other than the DFT levels of theory, including UHF and MC-SCF. The cause of the discrepancy between the experimental data and the theoretical calculations, as well as the cause of the discrepancy between the theoretical results obtained at different levels of theory, is a serious problem that needs to be addressed in the future theory development.

\section{Acknowledgement}

CPU time support from Interdiscplinary Centre for Mathematical and Computational Modelling in Warsaw is gratefully acknowledged.

\section{References}

1. Siegbahn, P.E.M. Theor. Chem. Acc. 2001, 105, 197-206

2. Waizumi, K.; Ohtaki, H.; Masuda, H.; Fukushima, N.; Watanabe, Y. Chem. Lett. 1992, 8, 1489

3. Borgstahl, G.E.; Parge, H.E.; Hickey, M.J.; Beyer Jr., W.F.; Hallewell, R.A.; Tainer, J.A. Cell 1992, 71, 107

4. Sundaramoorthy, M.; Kishi, K.; Gold, M.H.; Poulos, T. L. J. Biol. Chem. 1994, 269, 32759-32767

5. Wilce, M.C.; Bond, C.S.; Dixon, N.E.; Freeman, H.C.; Guss, J.M.; Lilley, P.E.; Wilce, J.A. Proc. Natl. Acad. Sci.USA 1998, 95, 3472-3477

6. Palcic, M.M.; Ripka, J.; Kaur, K.J.; Shoreibah, M.; Hindsgaul, O.; Pierce, M. J. Biol. Chem. 1990, 
265, 6759-6759

7. Yousefi, S.; Higgins, E.; Daoling, Z.; Pollex-Kruger, A.; Hindsgaul, O.; Dennis, J.W. J. Biol. Chem. 1991, 266, 1772-1782

8. Beyer, T.A.; Hill, R.L. J. Biol. Chem. 1980, 255, 5373-5379

9. Lee, J.O.; Bankston, L.A.; Arnaout, M.A.; Liddington, R.C. Structure 1995, 3, 1333-1340

10. Qu, A.; Leahy, D.J. Proc. Natl. Acad. Sci.USA 1995, 92, 10277-10281

11. Bethe, H. Ann. Phys. 1929, 3, 1933

12. Bethe, H. Z. Phys. 1930, 60, 218

13. Van Vleck, J.H. Phys. Rev. 1932, 41, 208

14. Cotton, F.A.; Wilkinson, G.; Gauss, P.L. Basic inorganic chemistry; Second Edition; John Wiley and Sons; 1987

15. Griffith, J.S. The Theory of Transition Metal Ions; Cambrdge University Press; 1971

16. Ohtaki, H.; Radnai, T. Chem. Rev. 1993, 93, 1157-1204

17. Cotton, F.A.; Daniels, L.M.; Murillo, C.A.; Quesada J.F. Inorg. Chem. 1993, 32, 4861-4867

18. Neilson, G.W.; Newsome, J.R.; Sandstrom, M.J. J. Chem. Soc. Faraday Trans. 2 1981, 17, 1245

19. Ozutsumi, K.; Koide, M.; Ishiguro, S. J. Phys. Chem. 1993, 97, 500-502

20. Marcus, Y. Chem. Rev. 1988, 88, 1475-1498

21. Akesson, R.; Pettersson, L.G.M.; Sandstrom, M.J.; Siegbahn, P.E.M.; Wahlgren, U. J. Phys. Chem 1992, 96, 10773-10779

22. Babu, C.S.; Lim, C.J. J. Phys. Chem. 1999, 103, 7958-7968

23. Sivaraja, M.; Stouch, T.R.; Dismukes, G.C. J. Am. Chem. Soc. 1992, 114, 9600-9602

24. Yague, J.I.; Mohammed, A.M.; Loeffler, H.; Rode, B.M J. Phys. Chem. A 2001, 105, 7646-7650

25. Loeffler, H.; Yague, J.I.; Rode, B.M. J. Phys. Chem. A 2002, 106, 9529-9532

26. Yague, J.I.; Mohammed, A.M.; Loeffler, H.; Rode, B.M. J. Mol. Struct: THEOCHEM 2003, 620, $15-20$

27. Van Vleck, J.H. J. Chem. Phys. 1935, 3, 807

28. Howard, P.J. J. Chem. Phys. 1935, 3, 813

29. Roothaan, C.C.J.; Rev. Mod. Phys 1951, 23, 69

30. McWeeny, R.; Dierksen, G. J. Chem. Phys. 1968, 49, 4852

31. Pople, J.A.; Nesbet, R.K. J. Chem. Phys. 1954, 22, 571

32. Moller, C.; Plesset, M.S. Phys. Rev. 46, 618 (1934)

33. Jonsson, B.; Roos, B.O.; Taylor, P.R.; Siegbahn, P.E.M. J. Chem. Phys 1981, 74, 4566

34. Roos, B.O.; Linse, P.; Siegbahn, P.E.M.; Blomberg, M.R.A. Chem. Phys. 1981, 66, 197

35. Becke, A.D. Phys. Rev. A 1988, 38, 3098

36. Lee, C.; Yang, W.; Parr, R.G Phys. Rev. B 1988, 37, 785

37. Slater, J.C. Quantum Theory of Molecular and Solids. Vol. 4: The Self-Consistent Field for Molecular and Solids; McGraw-Hill: New York; 1974

38. Vosko, S.H.; Wilk, N.; Nusair, M. Can. J. Phys. 1980, 58, 1200

39. Becke, A.D. J. Chem. Phys. 1993, 98, 5648

40. Perdew, J.P.; Burke, K.; Wang, Y. Phys. Rev. B 1996, 54, 16533 
41. Ohtaki, H.; Yamaguchi, T.; Maeda, M; Bull. Chem. Soc. Jpn. 1976, 49, 701

42. Shapovalov, I.M.; Radchenko, I.V. J. Struct. Chem. 1971, 12, 705

43. Beagley, B.; McAuliffe, C.A.; Smith, S.P.B.; White, E.W. J. Phys.: Condens. Matter 1991, 3, 7919

44. Caminiti, R.; Cucca, P.; Pintori, T. Chem. Phys. 1984, 88, 155

45. Caminiti, R.; Marongia, G.; Paschina, G. Z. Naturforsch. A 1984, 37, 581

46. Caminiti, R.; Cucca, P.; Monduzzi, M.; Saba, G.; Crisponi, G. J. Chem. Phys. 1984, 81, 543

47. Licheri, G.; Paschina, G.; Piccaluga, G.; Pinna, G. J. Chem. Phys. 1984, 81, 6059

48. Frisch, M.J.; Trucks, G.W.; Schlegel, H.B.; Scuseria, G.E.; Robb, M.A.; Cheeseman, J.R.; Zakrzewski, V.G.; Montgomery Jr., J.A.; Stratmann, R.E.; Burant, J.C.; Dapprich, S.; Millam, J.M.; Daniels, A.D.; Kudin, K.N.; Strain, M.C.; Farkas, O.; Tomasi, J.; Barone, V.; Cossi, M.; Cammi, R.; Mennucci, B.; Pomelli, C.; Adamo, C.; Clifford, S.; Ochterski, J.; Petersson, G.A.; Ayala, P.Y.; Cui, Q.; Morokuma, K.; Malick, D.K.; Rabuck, A.D.; Raghavachari, K.; Foresman, J.B.; Cioslowski, J.; Ortiz, J.V.; Baboul, A.G.; Stefanov, B.B.; Liu, G.; Liashenko, A.; Piskorz, A.; Komaromi, I.; Gomperts, R.; Martin, R.L.; Fox, D.J.; Keith, T.; Al-Laham, M.A.; Peng, C.Y.; Nanayakkara, A.; Gonzalez, C.; Challacombe, M.; Gill, P.M.W.; Johnson, B.; Chen, W.; Wong, M.W.; Andres, J.L.; Gonzalez, C.; Head-Gordon, M.; Replogle, E.S.; Pople, J.A; Gaussian 98, Revision A.7, Gaussian, Inc., Pittsburgh PA, 1998.

49. Jaguar 4.0, Schrodinger, Inc., Portland, Oregon, 2000

50. Dalton, a molecular electronic structure program, Release 1.2 (2001), written by. Helgaker, T.; Jensen, H.J.Aa.; Jorgensen, P.; Olsen, J.; Ruud, K.; Agren, H.; Auer, A.A.; Bak, K.L.; Bakken, V.; Christiansen, O.; Coriani, S.; Dahle, P.; Dalskov, E.K.; Enevoldsen, T.; Fernandez, B.; Hattig, C.; Hald, K.; Halkier, A.; Heiberg, H.; Hettema, H.; Jonsson, D.; Kirpekar, S.; Kobayashi, R.; Koch, H.; Mikkelsen, K.V.; Norman, P.; Packer, M.J.; Pedersen, T.B.; Ruden, T.A.; Sanchez, A.; Saue, T.; Sauer, S.P.A.; Schimmelpfennig, B.; Sylvester-Hvid, K.O.; Taylor, P.R and Vahtras, O

51. Montgomery, H.; Chastain, R.V.; Lingafelter, E.C. Acta Cryst. 1966, 20, 731-733

52. Clack, D.W.; Farrimond, M.S. J. Chem. Soc. (A) 1971, 299, 1971

(C) 2003 by MDPI (http://www.mdpi.org). Reproduction for noncommercial purposes permitted. 